\title{
Complutum
}

ISSN: 1131-6993

\section{Etnoarqueología, arqueología etnográfica y cultura material}

\author{
Alfredo González-Ruibal ${ }^{1}$
}

Recibido: 26 de enero de 2017 / Aceptado: 17 de febrero de 2017

Resumen. En este artículo se discuten los conceptos de etnoarqueología y arqueología etnográfica. En opinión del autor, ambos son problemáticos, el primero por su énfasis en la analogía, el segundo porque tiene poco de arqueológico (en el sentido de estudio de la cultura material). Si rechazamos la analogía como principal fundamento de la etnoarqueología, es necesario por lo tanto hablar de arqueología a secas. Sin embargo, ello nos lleva a buscar una nueva base para el estudio de sociedades actuales con metodología arqueológica. Aquí se defiende que dicha base es la cultura material. El resto del artículo se centra en la cuestión de la materialidad y lo que la arqueología puede aportar a comprender las sociedades del presente a través de ella.

Palabras clave: Etnoarqueología; Arqueología etnográfica; Materialidad; Cultura material; Sociedades no modernas.

\section{[en] Ethnoarchaeology, Ethnographic Archaeology and Material Culture}

\begin{abstract}
In this article, the concepts of ethnoarchaeology and archaeological ethnography are discussed. In the author's opinion, both are problematic, the former because of its emphasis on analogy, the second because it is scarcely archaeological (in the sense of the study of material culture). If we reject analogy as the main foundation of ethnoarcaheology, then it is necessary to speak about archaeology, full stop. However, this forces us to look for a new basis for the study of present societies with an archaeological methodology. Here it is argued that this basis is material culture. The remainder of the article focuses on the question of materiality and what archaeology can contribute to understanding contemporary societies through it.
\end{abstract}

Keywords: Ethnoarchaeology; Archaeological Ethnography; Materiality; Material Culture; Nonmodern Societies.

Sumario. 1. ¿Etnografía arqueológica o etnoarqueología? 2. Materialidad. 3. Ontología. 4. El inconsciente. 5. Las texturas de las cosas. 6. Conclusión.

Cómo citar: González-Ruibal, A. (2017): Etnoarqueología, arqueología etnográfica y cultura material. Complutum, 28(2): 267-283.

\section{1. ¿Etnografía arqueológica 0 etnoarqueología?}

El estudio de las sociedades contemporáneas como un fin en sí mismo parece ser el territorio exclusivo de la etnografía (o la sociología). La etnoarqueología, tradicionalmente, no ha estudiado las sociedades del presente en cuanto tales, sino como una forma de encontrar analogías para comprender mejor el pasado (David y Kramer 2001). Sin embargo, la investigación de sociedades no modernas actuales con metodología arqueológica (lo que se conoce habitualmente como etnoarqueología) puede ser una forma también de comprender dichas sociedades. Este ha sido el objetivo de mi investigación desde hace años (González-Ruibal 2014). Se podría decir que al renunciar a la analogía, al menos como una meta prioritaria, lo que sucede es que uno se convierte en etnógrafo. Sin embargo, mi trabajo no es, declaradamente, una 
etnografía, ni pretende serlo, pese a que utilice métodos etnográficos.

Cuando afirmo que mi trabajo no es etnografía, lo hago con el mayor respeto hacia esta disciplina, pero sin arrepentimiento. Recientemente la etnografía se ha convertido, en el campo de las ciencias sociales, en el método por excelencia y ha conseguido un aura de respetabilidad enorme. Todo el mundo quiere hacer etnografía: historiadores/as, psicólogos/ as, sociólogos/as, arqueólogos/as y, quizás significativamente, también empresas capitalistas (me refiero, por ejemplo, a la etnografía orientada al mercado: Arnould y Wallendorf 1994). En este contexto, no sorprende que se haya extendido el término "etnografía arqueológica". Sin embargo, su significado está lejos de ser evidente. Desde mi punto de vista, sugiero que es posible identificar al menos cuatro tipos de arqueología etnográfica, cada una de ellas con sus propias ventajas e inconvenientes.

El primer modelo de etnografía arqueológica es el que ha desarrollado la etnoarqueología. En este modelo se incluyen los trabajos realizados por arqueólogos/as, normalmente entre comunidades no modernas. Estos se caracterizan por tratar de responder preguntas arqueológicas, utilizar una metodología arqueológica y tener como objetivo central la producción de analogías (p.ej. Binford 1978; Watson 1979; Hodder 1982; Roux 2007; Lane 2006; Politis 2007, 2015a y b). En este sentido, la etnoarqueología trata de centrarse en el estudio de todos aquellos aspectos materiales que han sido tradicionalmente olvidados por la etnografía, tales como la tecnología, la gestión de los residuos, los paisajes, el abandono de los asentamientos, la construcción y organización de los espacios domésticos, o la biografía de los objetos ordinarios (vid. David y Kramer 2001). La finalidad última de estos estudios es proveer analogías que permitan interpretar el registro arqueológico, proponer y testar teorías de rango medio (Raab y Goodyear 1984; Wylie 1985; Schmidt 2010), así como entender los procesos mediante los cuales los contextos sistémicos (o vivos) se transforman en contextos arqueológicos (Schiffer 1972).

Aunque los fundamentos positivistas y nomotéticos que caracterizaron a la Nueva Arqueología, y por tanto a la etnoarqueología, han retrocedido en los últimos años ( $c f$. Roux 2007; Gallay 2011), la etnografía arqueológica tal y como es practicada por parte de la etnoarqueología continua sin estar interesada en el estudio de las sociedades vivas per se, o no lo tienen como objetivo primordial, sino que son tratados como proveedores de lecciones arqueológicas que pueden ser aplicadas a otros contextos, preferiblemente prehistóricos. Desde un punto de vista epistemológico, los problemas inherentes al razonamiento analógico han sido objeto de acalorado debate (Wylie 1985; David y Kramer 2001: 43-54) mientras que los problemas éticos asociados a este tipo de aproximaciones no han suscitado tanta controversia (aunque cf. Gosden 1999: 9). Sin embargo, parece obvio que estudiar otra gente por su potencial para ofrecer analogías no es la estrategia más postcolonial y que el procedimiento etnoarqueológico en sí mismo es un buen ejemplo de la negación de la contemporaneidad (coevalness) en su forma más cruda (González-Ruibal 2006).

Aunque no busco analogías y tampoco las propongo, esto no significa que mi trabajo no pueda utilizarse para realizar comparaciones. Después de todo, la arqueología compara todo el tiempo usando trabajos históricos y antropológicos, sin que estos sean considerados etnoarqueología por esa razón o el trabajo de comparación sea en sí mismo etnoarqueológico. Aunque desde mi punto de vista la etnografía arqueológica desarrollada por la etnoarqueología sea problemática, esto no significa que solo sirva para ofrecer analogías a la arqueología prehistórica. Algunos de los trabajos clásicos de la etnoarqueología (así como algunos trabajos recientes) han abordado el estudio de la compleja materialidad de las sociedades no modernas desde perspectivas novedosas (Watson 1979; Binford 1991; Horne 1994; Politis 2007). Lewis Binford, por ejemplo, demostró las grandes posibilidades que ofrecía la utilización conjunta de datos procedentes de entrevistas y de estrategias de observación participante junto con el uso de datos materiales procedentes del uso de métodos arqueológicos. Por otra parte, mi trabajo ha estado también influido por la etnoarqueología postprocesual, tal y como la desarrolló Ian Hodder (1987). Aunque poco practicada en general (pero $c f$. Lane 1994, 1996), la idea era ofrecer una alternativa a los estudios muy concretos y estancias breves en el campo propias de la etnoarqueología procesual. Hodder insistió en la necesidad de tomarse en serio el contexto histórico y cultural mediante la realización de estudios de larga duración. Su aproximación comparativa sobre amplias áreas geográficas 
compartidas por diferentes grupos también ha influido de manera importante en mi investigación (Hodder 1982; también Lemonnier 1986, 1992).

Un segundo tipo de etnografía arqueológica que se ha desarrollado durante la última década aproximadamente consiste en una práctica auto-reflexiva que presenta dos variantes. La primera de éstas puede definirse como un intento de traer a un primer plano lo que tradicionalmente ha sido considerado como el trasfondo (pintoresco) de toda investigación: las comunidades locales y los discursos y prácticas alternativas (Hamilakis y Anagnostopoulos 2009; Castañeda y Matthews 2008). Según Hamilakis y Agnastopoulos (2009: 67): la arqueología etnográfica es

"un espacio fuertemente controvertido y, en
consecuencia, transdisciplinario, transcultu-
ral y políticamente cargado; un espacio en
el que se pueden desarrollar múltiples con-
versaciones, compromisos, intervenciones
y críticas centradas en la materialidad y la
temporalidad. Este espacio fomenta la mi-
nimización de la distinción entre pasado y
presente, y entre diversos públicos e investi-
gadores igualmente diversos".

Un segundo subtipo lo conforman los estudios etnográficos del trabajo arqueológico por ejemplo, la arqueología de urgencia en una ciudad estadounidense o una excavación en las tierras bajas mayas (Edgeworth 2006). Este rasgo de la etnografía arqueológica muestra el modo en el que el conocimiento arqueológico se construye también mediante sus prácticas, herramientas e interacciones sociotécnicas.

Si en su inicio la etnoarqueología estuvo íntimamente ligada a cuestiones científicas y no mostró interés por el contexto local, este segundo tipo de etnografía arqueológica es justo lo contrario. Se caracteriza por su crítica al distanciamiento científico y por la importancia tanto de la autorreflexión como de su compromiso público (Meskell 2005; Hamilakis y Anagnostopoulos 2009). Aunque considero este tipo de etnografía arqueológica una compensación muy necesaria respecto a la desvinculación de la arqueología con los actores locales, creo que estas propuestas traen consigo dos cuestiones que pueden ser criticables.

En primer lugar, algunos de estos trabajos están mucho más centrados en las narrativas (narrativas sobre el pasado, sobre monumen- tos, sobre derechos) que en la propia materialidad o en las prácticas materiales (pero vid. Hamilakis 2011). Es decir, el peso recae demasiado en la etnografía y muy poco en la arqueología. Segundo, como en otras prácticas autocríticas de la arqueología y la antropología posmoderna y postcolonial, existe el riesgo de caer en el ensimismamiento y otorgar demasiada relevancia a la arqueología y al patrimonio en la vida de las personas.

En todo caso, no es que mi trabajo no pueda ser considerado como una etnografía arqueológica por las razones mencionadas, sino porque no intenta escudriñar la relación existente entre las personas que estudio y los conceptos y prácticas patrimoniales, tanto locales como foráneas. Sin embargo, me gustaría mantener lo que considero más necesario y atractivo de este tipo de aproximaciones: su preocupación crítica y postcolonial por los subalternos y la atención que presta a las prácticas culturales olvidadas y oprimidas.

Un tercer tipo de trabajo que en ocasiones recibe el calificativo de etnografía arqueológica es un tipo de estrategia utilizada por parte de la arqueología postprocesual para producir relatos del pasado más ricos y completos y para "sumergirse profundamente en las vidas de las personas" (Sinclair 2000: 475). Esta última búsqueda ha marcado fuertemente a la arqueología desde la década de 1970 (Deetz 1977; Hodder 1986) y es la causante de una amplia variedad de relatos arqueológicos sobre el pasado con el término "etnografía" en el título o el subtítulo (Tilley 1996; Verhoeven 1999).

Sin embargo, en mi opinión la arqueología postprocesual no ha buscado las descripciones densas en el lugar adecuado. Mientras que la arqueología ha tendido a asociar la descripción densa con la etnografía, y más particularmente con el trabajo de Clifford Geertz, lo cierto es que los historiadores de la Escuela de los Annales han venido produciendo narrativas densas, complejas y detalladas (iy del pasado!) mucho antes de que Geertz acuñara el término. Michael Shanks es el único arqueólogo del que tengo constancia que haya asociado de forma explícita la descripción densa con la Escuela de los Annales más que con la antropología simbólica (Pearson y Shanks 2001: 60). Además, a diferencia de Geertz, esta corriente mostró un interés evidente en la cultura material, quizás no de una manera arqueológica, pero ciertamente en sus relatos incorporaron los objetos (cf. Braudel 1966; Le Roy Ladurie 1975). 


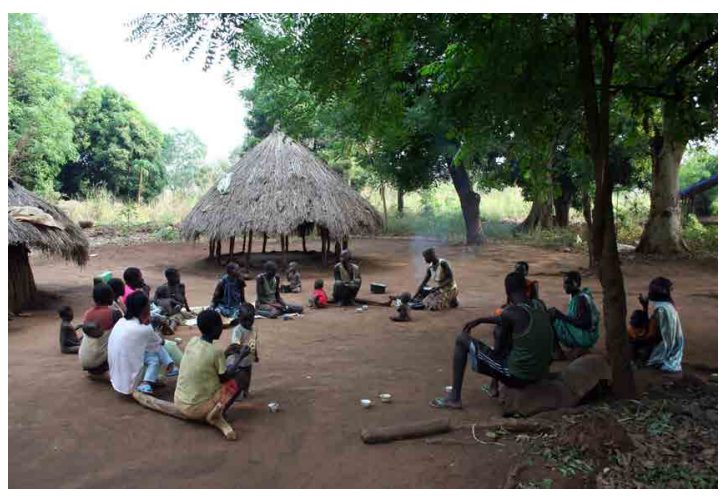

Figura 1. Gente de la etnia komo y opuuo comparten un café mañanero en la región de Gambela. Muchos de los poblados estudiados en mis investigaciones en Etiopía eran multiétnicos.

Por el contrario, la descripción densa de Geertz no está tan interesada en abordar el relato de las cosas y de los hechos, bien sean materiales o inmateriales, o en la densidad de las vidas vividas, como en desvelar las estructuras simbólicas que orientan pensamientos, discursos y acciones. El análisis cultural, afirma Geertz (1973: 20), consiste en "adivinar los significados y extraer conclusiones explicativas de las mejores conjeturas". La esencia de una aproximación semiótica a la cultura radicaría en "ganar acceso al mundo conceptual en el cual viven nuestros sujetos de manera que podamos, en un sentido amplio del término, conversar con ellos" (Geertz 1973: 24). Se trata básicamente de aprender otro idioma.

Por supuesto, una aproximación simbólica a la vida social (desentrañar significados) no es incompatible con descripciones densas de otro tipo más material. La intención de mi trabajo es probar que desentrañar los significados y manifestar el mundo material deberían ser parte de la misma tarea: hacer que nuestros relatos del mundo social resulten más complejos y profundos. A pesar de desarrollos recientes (incluyendo la antropología visual y los estudios de cultura material), no creo que la etnografía sea la mejor manera de ofrecer descripciones de los mundos sociales que son densos tanto desde un punto de vista simbólico como material. No encuentro entre la mayoría de etnógrafos/as un interés real en la materialidad en general (aunque sí en ciertos objetos específicos), si bien existen notables excepciones (Taussig 2004).

Un cuarto tipo de etnografía arqueológica trata de superar la ausencia de materialidad de las etnografías convencionales recurriendo a una perspectiva arqueológica que se aplica no al pasado, sino tanto al pasado como al presente en descripciones (materialmente) densas de regiones específicas (Forbes 2007; también Hamilakis 2011). Este es el tipo de etnografía arqueológica con el cual me siento más identificado: una etnografía arqueológica que tiene en cuenta la materialidad, la multi-temporalidad y las experiencias alternativas de la historia y los lugares. En todo caso, sigo pensando que en vez de estar preocupados por las etiquetas deberíamos simplemente usar el término "arqueología". Esto es lo que unifica nuestras diversas prácticas, independientemente del periodo de tiempo en el que centremos nuestro trabajo (el presente, el pasado reciente o el pasado remoto).

Si me siento incómodo con el concepto de etnografía arqueológica no es únicamente por razones teóricas. Metodológicamente, mi trabajo no se ajusta a los estándares usuales de la etnografía (ni tampoco lo he pretendido nunca). Entiendo por práctica etnográfica habitual al trabajo de un único investigador/a (o a lo sumo dos), que vive en una comunidad concreta durante prolongados períodos de tiempo y de forma continua, en los cuales aprende la lengua, puede conocer la comunidad en profundidad y establece relaciones de confianza con algunos de sus miembros.

Mi trabajo de campo en Etiopía, por ejemplo, fue desarrollado de forma interrumpida en 9 campañas entre enero de 2001 y marzo de 2010, con un total de cerca de 12 meses en el país, además de una visita preliminar de una semana en el año 2000 (González-Ruibal 2014). Durante este tiempo, visité Etiopía occidental durante ocho meses diferentes (enero, febrero, marzo, abril, junio, octubre, noviembre y diciembre) y algunos de los grupos con los que trabajé solo puede visitarlos durante uno o dos de esos meses. El área en el que se desarrolló el trabajo de campo tiene una superficie aproximada de $85.000 \mathrm{~km}^{2}$ (el tamaño de un país pequeño como Austria). En este amplio territorio viven alrededor de 21 grupos étnicos (bertha, gumuz, boro, gwama, komo, bambasi mao, hozo, seze, sith shwala, anfillo/busase, opuuo, añuak, nuer, sabu, majangir, agäw, oromo, amhara, kambata, hadiya y shekkacho) (Fig. 1).

A diferencia de un etnógrafo clásico, no pasé todo el tiempo con las mismas personas o en la misma localidad. De hecho, la esencia de 
este proyecto consistía en visitar cuantas más localidades, áreas y grupos posibles, con el objetivo de poder compararlos entre sí. Y no debería decir "yo" ya que nunca estuve solo. En todas las ocasiones fui acompañado de colegas, conductores, guías y traductores, aunque nuestro grupo nunca superó las seis personas (dos o tres investigadores y dos o tres asistentes) ni contó con menos de tres. Por otra parte, en nuestra investigación también llevamos a cabo trabajo arqueológico, incluyendo la excavación, prospección y levantamiento planimétrico de yacimientos prehistóricos, históricos y contemporáneos. Así pues, es evidente que mi investigación ha sido un trabajo colectivo ( $\mathrm{y}$ multidisciplinario) $\mathrm{y}$, en este sentido, es, otra vez, sensiblemente diferente de la etnografía clásica - en tanto que empresa solitaria - y muy similar a la arqueología.

La naturaleza de mi investigación en Etiopía me impidió involucrarme personalmente con la gente. Mis colegas y yo nunca pasamos más de dos semanas en una única localidad, y lo más habitual fue que las estancias se prolongaran únicamente tres o cuatro días. De esta manera, no hay mucha intersubjetividad en mi trabajo y muy poco de los procesos por los que habitualmente pasan los antropólogos durante su trabajo de campo. No hice amigos en las comunidades visitadas y siempre permanecí como un extraño total, aunque tanto mis relaciones como las de mis colegas con la gente con la que trabajamos fueron casi siempre muy amistosas. No he aprendido ninguna de las lenguas de las diversas comunidades (más allá de saludos y muchos nombres de cerámicas, utensilios agrícolas o partes de casas).

Sin embargo, la calidad de mi información es mejor cuando las entrevistas se han desarrollado en amhárico (del cual entiendo algo) que cuando se han desarrollado en oromo o en árabe sudanés, la otras lenguas francas utilizadas en Etiopía occidental. También mi información es mejor cuando he tenido que utilizar únicamente un traductor que cuando he tenido que utilizar dos. Afortunadamente, esto ocurrió únicamente en casos muy concretos - por ejemplo, con un ganza hablando en gwama a un gwama hablando en oromo a mi colega, que mentalmente traducía del oromo al amharico y luego al inglés (y yo traduciendo mentalmente del inglés al español, aunque todas mis notas fueron tomadas directamente en inglés). De esta manera, he tenido que depender en gran medida del trabajo de historiadores, sociólo- gos y antropólogos que han trabajado en la región para poder comparar mis observaciones.

Por tanto, mi investigación no puede ser calificada ni como etnografía, ni como etnografía arqueológica o etnoarqueología. Sin embargo, no pretendo inventar algo nuevo. Al contrario, lo que hago es arqueología, y la defiendo como tal, sin tratar de trascender sus limitaciones mediante los métodos etnográficos o de otro tipo.

Si la analogía no es la esencia de una arqueología del presente, tendremos que encontrar otro elemento que lo sustituya y sobre el que fundamentar nuestra práctica. Para mí, este elemento es la materialidad.

\section{Materialidad}

Cuando la antropología dejó de estar interesada en la historia, hacia la década de 1920, también perdió el interés por la cultura material, ya que la profundidad temporal y la materialidad estaban estrechamente vinculadas en el discurso histórico-cultural. Éste utilizaba los objetos para reconstruir trayectorias históricas profundamente especulativas. Los antropólogos, sin embargo, desecharon el estudio de la materialidad en general, incluidos sus aspectos valiosos (Olsen 2010).

Ha habido, por supuesto, un renacimiento en el interés por la cultura material en el seno de la antropología cultural (Miller 1998). Sin embargo, este interés ha sido parcial al menos por cuatro razones: 1) se ha centrado esencialmente en las cualidades simbólicas de los objetos y se han seleccionado únicamente aquellos objetos más fácilmente accesibles a la aproximación hermenéutica (Olsen 2010); 2) se ha pasado por alto la propia materialidad (Olsen 2003, 2010; Hodder 2012); 3) se han desarrollado estudios que no tienen en cuenta los colectivos de cosas y sus múltiples relaciones, sino los objetos individuales; 4) se ha olvidado en gran medida la producción y el descarte (pero vid. Douny 2007) privilegiando en su lugar el consumo (González-Ruibal 2006). Estos problemas afectan indistintamente a las diferentes escuelas modernas de estudios de cultura material (González-Ruibal 2006: 119120).

Así pues, la tradición alemana ha mantenido una visión totalizante de la cultura material, que queda claramente patente en las diversas monografías que sobre las comunidades del 
África subsahariana continúan publicándose (vid. una revisión crítica en Hahn 2003). Incluso aunque hayan mantenido, y en algunos casos desarrollado, el interés por la densidad material de la antropología temprana, esta aproximación presenta tres problemas distintos: primero, ya no abordan de forma conjunta el estudio de objetos y personas (como ocurría en la etnografía de finales del siglo XIX e inicios del XX), sino que únicamente tratan los objetos; segundo, raras veces tienen en cuenta la tecnología occidental; y, finalmente, normalmente trabajan con marcos sociológicos desfasados (aunque vid. Hahn 2003).

La tradición francófona, siguiendo la senda establecida por Durkheim y Mauss, es mucho más rica desde un punto de vista sociológico, pero raramente es totalizante ( $v i d$. la revista Téchniques et Culture). Así pues, los Pétréquins estudian hachas (Pétréquin y Pétréquin 1993) o cerámicas (Pétréquin y Pétréquin 1999) de forma sumamente detallada y con una notable sensibilidad sociológica, pero no exploran las relaciones existentes entre ellos, dejando de lado lo que podríamos llamar la "ecología de los objetos" en las sociedades melanesias que estudian. De hecho, con algunas excepciones importantes (Lemmonier 1992), pocos autores abordan el estudio de conjuntos completos de materiales, a pesar de que Pierre Lemonnier lamentaba "la escasa posibilidad de comprender la cultura material de cualquier sociedad estudiando únicamente unos pocos artefactos o, peor, estudiando artefactos de un solo tipo" (Lemonnier 1992: 9). Por otro lado, algunos antropólogos clásicos como Godelier, Meillassoux o Clastres raramente tuvieron en cuenta la cultura material; a lo sumo consideraron los objetos como metáforas de hechos sociales más amplios (p. ej. Godelier 2002).

Por último, la escuela británica, tras el giro postcolonial reflejado en el Journal of Material Culture, ha centrado su enfoque predominantemente sobre artefactos occidentales, y también nos ha privado de los enfoques holísticos de las primeras etnografías. Esta corriente nos ha apartado más incluso de otras maneras de usar, pensar y relacionarse con la cultura material. Esto es lo que sucede cuando los antropólogos vuelven de los trópicos, tal como critica Latour (1993: 100). Así pues, los especialistas en cultura material han estudiado principalmente objetos industriales, desde coches (Miller 1998) a radios (Schiffer 1991) pasando por arte de trinchera (Saunders 2003) o lencería (Storr 2003). E incluso cuando su interés se detiene más allá de su país, estos especialistas parecen interesarse principalmente en estudios parciales -como ocurre, por ejemplo, con el trabajo de Glassie (1999), por otra parte estupendo, con capítulos sobre alfombras y cerámicas- o en productos occidentales en contextos no occidentales (Miller 1998). Contrariamente a lo que Lemonnier recomienda, en esta corriente de estudio las decoraciones del hogar, pantalones vaqueros, coches o teléfonos móviles se estudian normalmente de manera aislada. Como hemos visto, en algunos casos la etnoarqueología ha sido una manera de involucrarse más plenamente con la materialidad de comunidades tradicionales y con complejos conjuntos de objetos y personas, pero los problemas en este caso son los usos analógicos a los que se ha sometido a los objetos y la escasa interpretación de los datos.

Se puede defender, por lo tanto, que la arqueología se halla en una buena posición para superar estos defectos, ya que tradicionalmente ha estudiado tanto los símbolos como la materialidad, así como amplios colectivos de humanos y cosas, o también chaîne operatoires completas (Skibo y Schiffer 2008; Olsen et al. 2012). En esto, la arqueología ha mantenido el interés de la etnografía temprana por el conjunto de la materialidad de la vida social, desde la forma de atar un nudo al uso de una casa ritual. Marcel Griaule capta perfectamente este interés cuando afirma que "todas las actividades humanas se traducen en objetos, y podemos decir que, teóricamente, sería posible conocer una sociedad basando nuestras observaciones en todo lo que ha creado o utilizado y complementándolo todo con el máximo de documentación" (Griaule 1938: 7). Al haber permanecido fiel a la materialidad en toda su variedad y complejidad, la arqueología debería ser capaz de emprender el estudio no sólo de las culturas materiales pasadas, sino también de las actuales (Harrison 2011). Sin embargo, para hacer justicia a la relevancia de las cosas debemos considerar tres cuestiones fundamentales: la ontología, el inconsciente y la textura.

\section{Ontología}

Desde finales de la década de 1970 la arqueología y la antropología han prestado mucha atención a los aspectos simbólicos de la cultura material (Hodder 1982). Los artefactos se 
entienden como cargados de significado, como símbolos, y, por tanto, los actores sociales los pueden manipular de forma activa para alcanzar ciertos fines, como adquirir o legitimar estatus, alcanzar el poder, marcar la identidad étnica, negociar el yo individual o definir el género (Hodder 1982: 85-86). Al mismo tiempo, se ha argumentado que se debe conceder a los objetos un papel más activo en la cultura. Desde el punto de vista postprocesual la cultura material no es únicamente un reflejo de la sociedad, sino que está profundamente implicada en su conformación y transformación: "la cultura material transforma, más que refleja, la organización social según las estrategias, creencias, conceptos e ideologías de los grupos" (Hodder 1982: 212). A pesar de referirse a "símbolos en acción" y el papel activo de la cultura material, la teoría postprocesual fomentó estudios de actores humanos manipulando diversos artefactos para diversos fines. Así pues, por ejemplo, Ian Hodder (1982: 121) afirmó que "el ejemplo de los lozi muestra cómo los grupos dominantes puede manipular cuidadosa y conscientemente los símbolos materiales con el fin de justificar y legitimar su poder" (el énfasis es mío).

Desde esta perspectiva, los artefactos no son sino un medio en manos de la gente que lo utiliza en sus múltiples relaciones sociales - una postura similar a la que defendía la arqueología conductual (Skibo y Schiffer 2008). Estas perspectivas continúan siendo dominantes. Para Christopher Tilley (2006: 63), "la creación de objetos es la fabricación del yo social" y se argumenta lo mismo en referencia al intercambio y consumo de objetos. Así pues, las conchas kula son ejemplos de objetos utilizados en la construcción de las identidades sociales a través del entrelazamiento de las biografías de las conchas y las personas que se encuentran en circulación constante (Tilley 2006: 63).

Críticas recientes, a menudo derivadas de las perspectivas postprocesuales, insisten en que el significado y simbolismo de la cultura material no es más que una única faceta de los objetos y que éste no es siempre el más crucial (Knappett 2002, 2012; Olsen 2003, 2010; Jones 2007; Hodder 2012). Esto no implica afirmar que el significado de los objetos no es importante. De hecho, la interpretación del significado social ha sido siempre un objetivo importante en mi trabajo. En este sentido, la crítica hacia los excesos derivados de la her- menéutica nos recuerda que los objetos son algo más que una tabula rasa sobre la cual podemos inscribir nuestras necesidades, deseos, ideas y valores: los objetos son parte inextricable de nosotros mismos, una extensión de nuestros cuerpos (Witmore y Webmoor 2008). Nosotros somos no sólo a través del uso de los objetos, sino también mediante la fabricación de objetos (Dobres 2000; Olsen et al. 2012: 157-195).

Este último aspecto ha sido descuidado en los estudios de cultura material (en favor de un énfasis en el consumo), principalmente a causa de la limitada agencia que sobre la producción de objetos presenta la gente en el seno de las sociedades industriales y post-industriales. Una de las ventajas más importantes a la hora de estudiar las comunidades no modernas es la oportunidad que éstas nos ofrecen para entender la relevancia ontológica de la producción (Ingold 1990; Dobres 2000; González-Ruibal et al. 2011). Tomarse en serio la materialidad implica repensar algunas suposiciones que se han dado por hecho en las ciencias sociales, como la centralidad absoluta de la agencia humana. En esta nueva perspectiva, los papeles sociales se distribuyen indistintamente entre actores humanos y no humanos (Latour 1993; Hodder 2012; Olsen et al. 2012).

Una aproximación ontológica a los objetos considera que las ecologías de humanos y no-humanos están entrelazadas en el mismo plano existencial (Webmoor y Witmore 2008). Sin embargo, estas ecologías son profundamente diferentes en distintas sociedades. Precisamente, las aproximaciones ontológicas recientes enfatizan esta diversidad (vid. Alberti y Marshall 2009; Alberti et al. 2011). Lo que no difiere es el hecho de que los humanos y los objetos no pueden separarse. Esto significa que un arco no tiene menos importancia que un espíritu y que un recipiente cerámico merece, a priori, tanta atención como el hermano de la madre. Esto no significa que todos los artefactos sean iguales, de igual manera que ningún antropólogo/a defenderá que todas las posiciones de parentesco o que todos los rituales tienen la misma importancia en una sociedad concreta. Por lo tanto, aunque me referiré a tipos muy diferentes de objetos, en mi discurso algunos artefactos desempeñarán un papel más destacado que otros, porque tienen un papel ontológico más crucial. Esos artefactos podrían considerarse en algunos casos como tecnologías materiales del yo. En otra parte, 


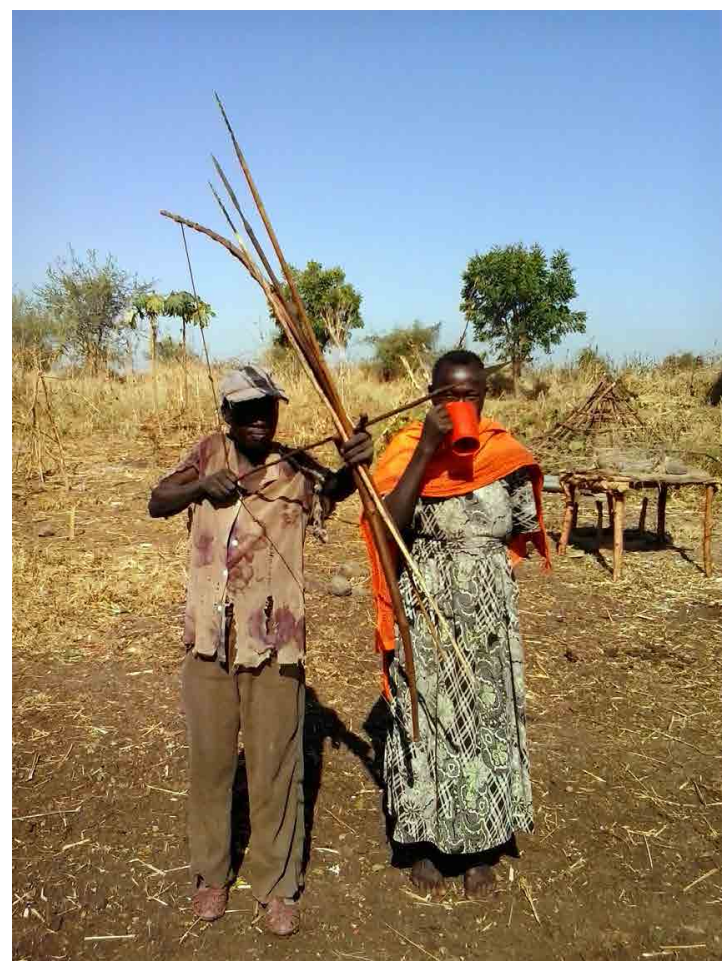

Figura 2. Una imagen perfecta de la tecnología del yo y los objetos nucleares: un hombre y una mujer gumuz posan espontáneamente con dos de los elementos materiales constitutivos de su cultura - el arco y la cerveza de sorgo.

hemos defendido que una tecnología del yo podría ser identificada por los siguientes rasgos (González-Ruibal et al., 2011: 14):

(1) Los objetos preferiblemente tienen que haber sido fabricados por su propietario o propietaria.

(2) $\mathrm{Su}$ fabricación, uso y mantenimiento implican una importante inversión de tiempo y requieren tanto concentración intelectual como el aprendizaje de habilidades psicomotrices específicas.

(3) Deben ser reconocidos por otros individuos como una propiedad personal (e incluso intransferible).

(4) Tiene que ser un objeto hasta cierto punto individualizado (es decir, tiene que ser claramente distinguible de otros artefactos similares pertenecientes a otras personas).

(5) Tiene que estar íntimamente ligado a su propietario/a (a menudo se lleva encima incluso cuando no se lo está utilizando).
(6) Debe tener un carácter corpóreo, prostético, como una extensión del cuerpo humano.

(7) Su fabricación y uso debe ser frecuente e implicar una rutina: la repetición de los mismos actos es fundamental en el mantenimiento de la seguridad ontológica y en la continuidad del ser.

(8) Cuando el dueño/a muere, tiene que enterrarse con él o ella o ser destruido; no suelen heredarlo o utilizarlos otras personas tras su muerte.

Es importante tener en cuenta que este yo no tiene por qué ser el yo individual propio de las modernidad occidental; puede ser un yo relacional de las comunidades no modernas (Hernando 2012). Algunos objetos que he tenido ocasión de estudiar y que pueden ser considerados tecnologías del yo son los arcos y flechas de los hombres Gumuz o los collares y portabebés de las mujeres del mismo grupo étnico (González-Ruibal 2014) (Fig. 2). Sin embargo, no todos los artefactos que son ontológicamente cruciales en la construcción de un determinado grupo de gente pueden describirse fácilmente como una tecnología del yo. Existen otros conceptos útiles para referirse a objetos que poseen valor ontológico, independientemente de si son o no tecnologías del yo. Uno de ellos, es el de resonador perisológico, propuesto por Lemonnier (2012), para diferenciar objetos especiales de "objetos mundanos". Como el nombre implica, se trata de artefactos que "resuenan" con otros fenómenos y de forma redundante. La perisología es una "figura de estilo que consiste en enfatizar una idea repitiéndola de diferentes formas" (Lemonnier 2012: 128). A través de su uso y fabricación, los resonadores perisológicos asocian campos de la vida social distintos, cuyas relaciones a veces no son evidentes. Esta capacidad de unir distintos campos de experiencia los hace irreemplazables dentro de la cultura: su desaparición puede llevar a una transformación radical de la cultura. Un concepto homólogo es el de los objetos nucleares. Ernst Boesch (1991: 333) define un objeto nuclear (core object) como "aquel que, por sus usos y conexiones rituales, parece ser vital para la auto-definición de una cultura". Un objeto nuclear puede ser la cabaña ritual de los mao o la cerámica para cerveza de los bertha (González-Ruibal 2014). Sin embargo, aunque no todos los objetos nucleares son tecnologías del yo, toda tecnología del yo es siempre un objeto nuclear. 


\section{El inconsciente}

El desplazamiento hacia la ontología implica otro cambio de perspectiva, que no ha sido plenamente desarrollado hasta el momento: la necesidad de movernos desde el ámbito de la consciencia al de la inconsciencia. Este es un cambio implícito en el desplazamiento desde el énfasis en la simbolización y comunicación hacia la preocupación por la ontología. Ésta implica que la relación entre humanos y no humanos es previa a la simbolización y, por tanto, más profunda y menos evidente para los actores humanos. El énfasis en la ontología implica repensar y evaluar críticamente el vocabulario común en la arqueología postprocesual y en los estudios de cultura material que incluyen términos como "estrategia", "negociación" y "manipulación" que inevitablemente implican un actor humano consciente y un mundo material pasivo. Desde esta perspectiva, las cosas sólo se activan a través de la agencia humana. Sin embargo, desde un punto de vista ontológico los actores no humanos se encuentran siempre activos y funcionan de forma independiente a la acción simbólica. Por supuesto, éstos pueden cargarse de significado $\mathrm{y}$, en algunos contextos (tales como contactos culturales o crisis sociales) pueden comenzar a ser manipulados conscientemente. Sin embargo, esta última situación, al menos en sociedades no modernas tradicionales, debe considerarse como la excepción, no la regla. En este sentido, la noción de doxa de Pierre Bourdieu puede ser útil (cf. Pauketat 2001; Silliman 2001). De acuerdo con el sociólogo, cuando existe una correspondencia casi perfecta entre el orden objetivo y los principios de organización subjetivos los mundos naturales y sociales aparecen como autoevidentes. A esta experiencia la podemos denominar doxa, para distinguirla así de las creencias ortodoxas o heterodoxas que implican la conciencia y reconocimiento de la posibilidad de creencias diferentes o antagónicas (Bourdieu 1977: 164).

El problema que presentaban los trabajos arqueológicos y antropológicos surgidos bajo la égida del posmodernismo es que su énfasis en la ortodoxia y la heterodoxia ha eclipsado el estado mucho más común de los objetos, es decir, la doxa, la realidad irreflexiva de la vida social ordinaria. Esta realidad irreflexiva es subrayada por otro sociólogo, Paul Connerton (1989), cuando se refiere a las "prácticas incorporadas" (incorporating practices), tales como los gestos corporales y el movimiento. Estas son esencialmente inconscientes, en oposición a las "prácticas inscritas" (inscribing practices), a las que se ha otorgado prioridad tradicionalmente en las ciencias sociales inclinadas hacia la hermenéutica (Connerton 1989: 100-101). Sin embargo, Connerton se equivoca cuando considera que estas prácticas casi no dejan evidencias (Connerton 1989: 102; vid. crítica en Olsen 2010: 123-124). La arqueología documenta en muchas ocasiones estas prácticas. Por ejemplo, al analizar la distribución de artefactos y áreas de actividad en el interior de una casa la arqueología puede identificar movimientos corporales y, por tanto, prácticas incorporadas (Hodder y Cessford 2004).

En cierto sentido, un desplazamiento hacia el inconsciente implica que el arqueólogo/a deba actuar como un psicoanalista. Es bien sabido que los psicoanalistas no quieren simplemente que sus pacientes les cuenten aquello que saben pero que no cuentan a otras personas. También aspiran a conocer aquello de lo que los propios pacientes no son conscientes. Mediante el estudio de la materialidad y de las prácticas materiales, pues, la arqueología debería ser capaz de desentrañar aquello que los propios sujetos de estudio desconocen, o apenas son capaces de vislumbrar, de sí mismos. La profunda conexión existente entre la cultura material y el inconsciente ya ha sido defendida en arqueología y antropología. Leroi Gourhan afirmaba que la "consciencia crepuscular" (conscience crépusculaire) era el estado más común de las prácticas técnicas más comunes (Leroi-Gourhan 1965: 20). Por su parte, Henry Glassie (1975: 11) afirmaba que "las recurrencias [en la cultura material] no pueden ser explicadas únicamente atendiendo a la conciencia, porque el patrón histórico es producto tanto del insconsciente como de la consciencia". Como hemos visto, el inconsciente es también crucial en la teoría de la práctica, a pesar del secuestro al que ha sido sometido ésta por parte de la academia anglosajona para satisfacer sus preocupaciones sobre la agencia. De acuerdo con Schwartz (1997: 10), para Bourdieu, "el sociólogo es al inconsciente social de las sociedades lo que el psicoanalista es al inconsciente del paciente". El propio Bourdieu se percató de este paralelismo cuando en La dominación masculina (2001: 3-5) defiende "una arqueología objetiva de nuestro inconsciente", un socioanálisis que sea capaz de ob- 


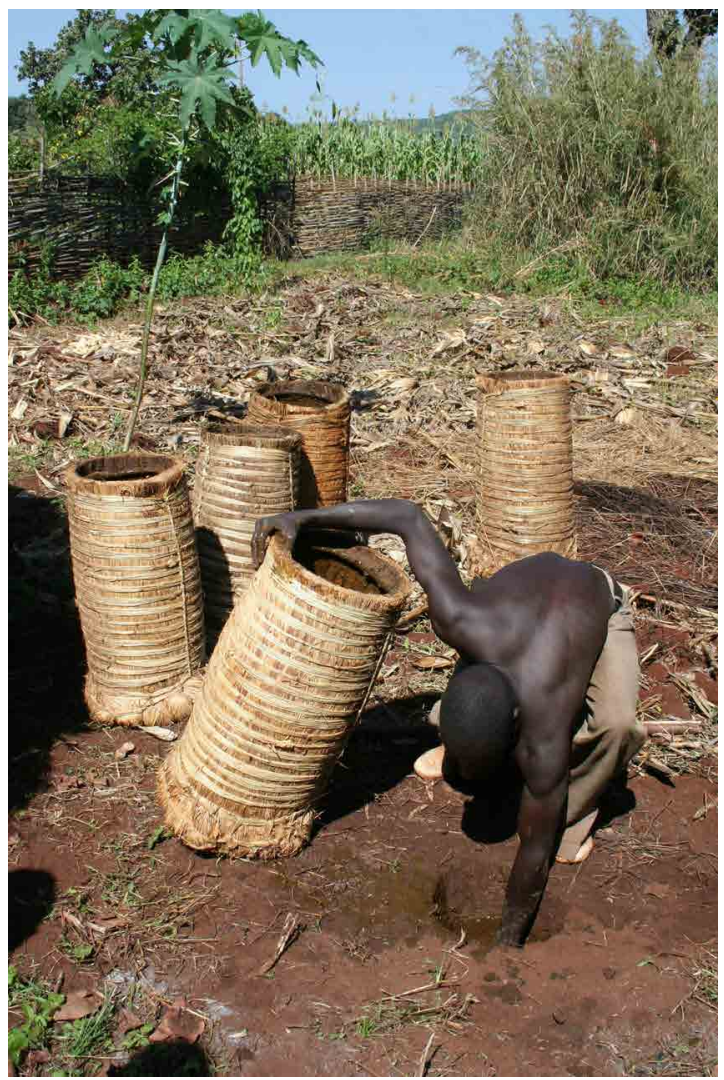

Figura 3. El desecho de la cultura: un hombre mao (Sith Shwala) forra de estiércol sus colmenas.

jetivar las categorías de nuestro inconsciente androcéntrico.

No es necesario buscar entre los trabajos de corte estructuralista para hallar afirmaciones que enfaticen el inconsciente. Por ejemplo, Evans-Pritchard (1970: 232) consideraba que las lanzas de los Nuer estaban investidas de un "simbolismo más profundo" (en comparación con los sacrificios, ritos de paso y rituales sanadores) de los cuales los Nuer no eran plenamente conscientes: "existe un simbolismo más profundo que se encuentra tan inserto en la acción ritual que su significado no es obvio ni explícito". El propio Ian Hodder (1982: 180), en su estudio del arte personal nuba, afirma que "es difícil apreciar lo que la información verbal podría aportar al análisis. En este sentido el arqueólogo está en la misma posición que el estudiante de arte y diseño de las sociedades modernas". En otro trabajo, el mismo autor defiende que "debería quedar claro que las ideas que se reconstruyen desde la arqueología no son necesariamente pensamientos conscientes que se hubieran expresado si pudiéramos via- jar atrás en el tiempo y hablar con la gente en la prehistoria" (Hodder 1992: 18).

Aquello que se dice no agota el significado. Los objetos pueden transmitir significados no explícitos. Es más, "existen vacíos, sombras, silencios y ausencias que no están simplemente fuera del discurso, sino que a menudo son excluidos estructuralmente de este" (Lucas 2004: 117). Estos silencios pueden ser rastreados a través de los comportamientos materiales. Sin embargo, en la arqueología se ha optado por evitar las ausencias e interpretaciones y centrarse en la negociación activa y en la agencia, olvidándose así de la relevancia del inconsciente. Desde mi punto de vista, la arqueología puede realizar contribuciones importantes en este campo, entre otras cosas porque la esencia de la disciplina consiste, tal y como afirmaba Deetz (1977) en trabajar con "pequeñas cosas olvidadas".

Las pequeñas cosas olvidadas son también el material con el que trabajan los psicoanalistas. Freud (Freud y Phillips 2006: 242) afirmó que "lo verdaderamente novedoso del psicoanálisis y uno de los aspectos más característicos de éste es su énfasis en las cosas que se han descuidado, descartado como un error". El psicoanálisis halló esas cosas desatendidas "en el montón de basura, por así decirlo, de nuestras observaciones" (citado en Ginzburg 1980: 10). En una línea similar, Walter Benjamin se refiere a los "rincones desconocidos de la existencia", a los materiales olvidados (los "detritos de la historia"), capaces de revelar elocuentemente la naturaleza del pasado (Benjamin et al. 1994: 505). Carlo Ginzburg (1980) coloca a Freud en la misma línea que el crítico de arte decimonónico Giovanni Morelli, quien identificó la autoría de los grandes maestros de la pintura centrándose en el análisis de los lóbulos de las orejas, dedos de manos y pies e incluso de los clavos que se aparecían en las pinturas.

Aún podríamos añadir otra categoría de investigadores: quienes siguen la olvidada y vilipendiada antropología histórico-cultural. Como Freud, Morelli y Benjamin, esta antropología también se dedicó a la búsqueda de rastros, cosas olvidadas, errores, lagunas y, en general, lo banal. Las huellas antropológicas fueron frecuentemente materiales: un modo concreto de realizar un nudo o tejer una cesta, el diseño específico de una escarificación, un tipo de hogar o un techo de paja. La antropología histórico-cultural construyó su discurso 
con estos materiales. El hecho de que sus interpretaciones fueran a menudo extravagantes o directamente erróneas no debería hacernos olvidar que pertenecen al mismo "paradigma de la prueba" (evidential paradigm) (Crossland 2009). En este sentido, Laurent Olivier (2008: 216) afirma que "incluso enterrado, mutilado o ignorado, el pasado remoto olvidado por la memoria continúa expresándose en el presente, de alguna manera a través de todas las evidencias posteriores". Lo que Olivier afirma al comparar el psicoanálisis y la arqueología podría haber sido defendido por cualquier antropólogo de principios del siglo XX al analizar sus datos materiales procedentes de sociedades africanas o sudamericanas.

La arqueología también trabaja con los detalles banales, con lo olvidado y lo reprimido. Como la arqueología que pretende ser, mi trabajo sobre sociedades no modernas ha prestado también atención al desecho, a lo que ha quedado descartado en las observaciones etnográficas. Excava, de hecho, en el mismo vertedero en el que comenzaron a excavar la antropología evolucionista y difusionista. Se centra en el estudio de cabañas y cercas, arcos y flechas, lanzas, colmenas y calabazas para almacenar miel, cerámicas y escarificaciones (González-Ruibal 2014) (Fig. 3). Sin embargo, a diferencia de lo que ocurre en la arqueología prehistórica, en la que únicamente se pueden analizar artefactos, en los contextos vivos que estudio puedo comparar los rastros materiales, las prácticas y los gestos con los discursos. Los discursos de los grupos dominantes, de los dominados e incluso de quienes no son ni amos ni esclavos: los viajeros y cronistas que escribieron sobres las gentes con los que he trabajado. Sin embargo, la arqueología prehistórica también puede comparar los usos hegemónicos de la cultura material y aquellos que escapan a la apropiación consciente.

Se podría argumentar que un enfoque en lo inconsciente va en contra del análisis de ciertos temas, como el de la resistencia. Diversos autores, de hecho, argumentan que toda resistencia debe ser consciente (vid. debate en Hollander y Einwohner 2004). Entonces, ¿cómo es posible desarrollar una arqueología de la resistencia? Mi premisa de partida es que cuando alguien resiste lo hace no solamente de un modo activo y consciente, sino que también lo hace involuntariamente. Esta está estrechamente relacionada con la ontología política de la resistencia: la resistencia no es solo una acción o grupo de acciones que se ejecutan, sino una forma de ser. Los gestos corporales y las maneras de usar y fabricar cosas (gestos técnicos), que existen de forma completamente inconsciente, pueden convertirse en actos cotidianos de resistencia y ser reconocidos como tales por otros. Por ejemplo, uno puede ir desnudo conscientemente, desafiando así las reglas hegemónicas que prescriben la ocultación del cuerpo en público y, al mismo tiempo, exhibir una hexis corporal inconsciente (como una manera concreta de portar una cerámica) que permite a los miembros del grupo dominante ser conscientes de la existencia de un ethos diferente en el trabajo. La resistencia en sociedades igualitarias que se enfrentan a un Estado es una actividad a tiempo completo, que continúa en marcha, al igual que el cerebro, cuando uno duerme.

\section{Las texturas de las cosas}

En las secciones previas he explorado lo que podríamos denominar la profundidad de las cosas, lo que está más allá de la superficie y tiene que ser "excavado": las relaciones ontológicas profundas que unen a las personas y a las cosas, y la naturaleza inconsciente de una parte importante de nuestras relaciones materiales con el mundo -incluyendo, algunas veces, la resistencia. En este punto regresamos a la superficie (Harrison 2011). En primer lugar, uno podría preguntarse si la superficie de las cosas importa. Incluso aquellos que normalmente no tienen en cuenta los objetos admiten, o al menos algunos de ellos, que son importantes, en el sentido que materializan significados y relaciones sociales. Pero, la superficie de las cosas apenas se tiene en consideración.

Por superficie entiendo aquí lo que puede ser experimentado sensorialmente: la textura de las cosas. Hasta hace escaso tiempo, la sensorialidad (sonido, gusto, tacto y olfato) ha estado muy ausente en los discursos etnográficos (vid. crítica en Witmore 2006) y cuando se ha analizado, la etnografía ha estado más interesada en interpretar y traducir el significado cultural de las experiencias sensoriales en diferentes contextos (una excepción notable es Taussig 2004). Pero ¿qué ocurre con las texturas sensoriales del mundo que se resisten a la inscripción (Witmore 2006: 271; también Hurcombe 2007; Witmore 2009)? Las cosas en sí mismas han estado ausentes de las mono- 


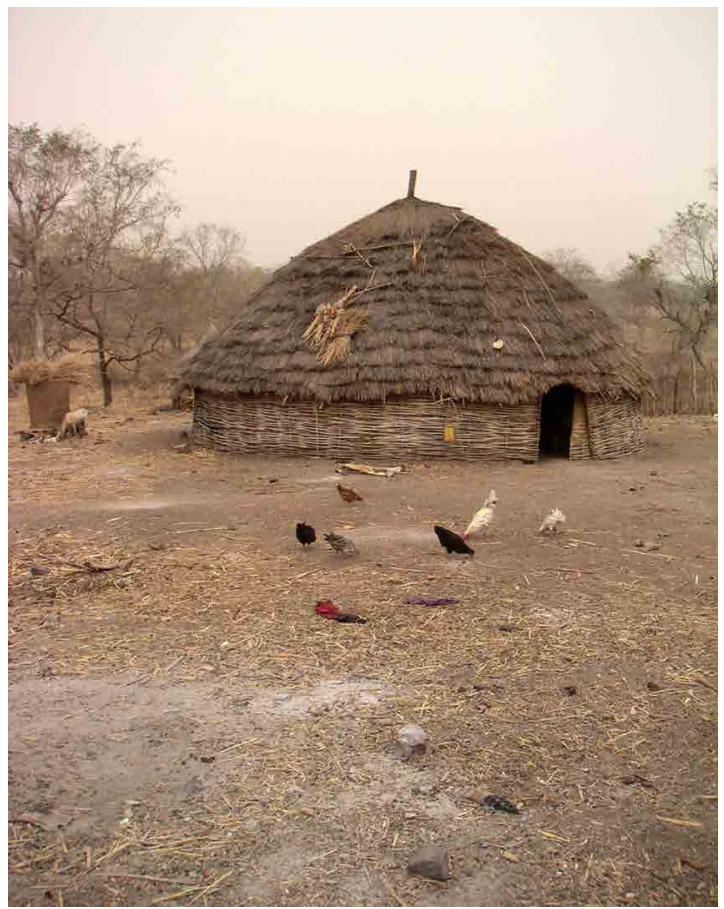

Figura 4. La textura de las cosas: distintas áreas de actividad frente a una cabaña gumuz identificadas por cenizales, piedras y tierra pisada.

grafías etnográficas desde la desaparición de la cultura material en la década de 1920. Directamente relacionada con esta cuestión es la limitada presencia de imágenes en las etnografías tradicionales, aspecto confirmado en cada una de las monografías producidas sobre la región de Etiopía en la que he trabajado (Evans-Pritchard 1970, 1992; James 1979, 1988; Jedrej 1995; Theis 1995). En las escasas imágenes contenidas en estos estudios, la gente ocupa invariablemente el primer plano, mientras que la materialidad de la vida cotidiana apenas puede percibirse en los fragmentos borrosos del fondo que apenas podemos atisbar. La cerámica es, en el mejor de los casos, simple atrezo y las cabañas, un escenario en el cual los seres humanos llevan la voz cantante.

Si existe cierta percepción de que describir la materialidad de las cosas, cuerpos y paisajes no es el trabajo apropiado de la etnografía, fotografiarlos, además, se considera una empresa colonialista y cosificadora. Esto es, naturalmente, cierto. No es mera casualidad que las monografías ilustradas más profusamente pertenezcan a los antropólogos más colonialistas que trabajaban en la región (Grottanelli 1940). Se ha demostrado ampliamente que las fotografías etnográficas son voyeristas e inqui- sitoriales, pero lo mismo se puede decir de los textos (Rosaldo 1986), y esto no ha impedido a los etnógrafos continuar entrevistando gente (a menudo sobre cuestiones muy íntimas) y exponer las vidas privadas de sus sujetos de investigación. La crítica de la investigación visual y etnográfica ha fomentado el desarrollo de formas de trabajo de campo éticamente más responsables. Sin embargo, lo cierto es que la crítica a lo visual ha eliminado la visualidad de las etnografías tradicionales (en su mayor parte, las imágenes se han visto confinadas a monografías y revistas especializadas), mientras que la crítica a los textos etnográficos ha alentado nuevas formas de escribir y relacionarse con los sujetos de estudio.

En marcada oposición a la sobriedad de las etnografías tradicionales destacan los libros ilustrados de gran formato sobre "tribus salvajes" - un buen ejemplo para el caso de Etiopía es Giansanti (2004). Las cosas no tienen mucho espacio en estos libros, pero las texturas de la vida cotidiana se manifiestan claramente: la sangre, el barro, la paja, el ocre y el polvo destacan prominentemente en estas poderosas narrativas visuales. Es cierto que existe un sesgo claro hacia las materias primas asociadas con un (supuesto) mundo primitivo. Sin embargo, estos libros de fotografía destinados al gran público nos permiten imaginarnos mejor cómo es la vida física, por ejemplo, de un poblado surma, que a través de las etnografías tradicionales. Huelga decir que estos libros ofrecen relatos distorsionados, idealizados y superficiales. No es mi intención defenderlos sino todo lo contrario. Es deplorable que la expresión visual de la riqueza de otros mundos se haya dejado tradicionalmente en manos de viajeros inexpertos. Pienso que tenemos que recuperar tanto las texturas del mundo como "el ruido, el alboroto y la conmoción asociadas a las cosas, todas esas cualidades que de otro modo se desvanecen en un segundo plano" (Witmore 2009: 521) y convertirlas en parte relevante de nuestra investigación. La arqueología está bien equipada para afrontar este reto, ya que nunca ha abandonado las texturas materiales (Fig. 4).

Lo que propongo simplemente es transferir el modo en el que los arqueólogos/as median con la materialidad cotidiana de mundos pasados a los contextos presentes. De hecho, esto no es nuevo. Es lo que la etnoarqueología viene haciendo desde finales de la década de 1950 (aunque, como hemos visto, con otros objeti- 


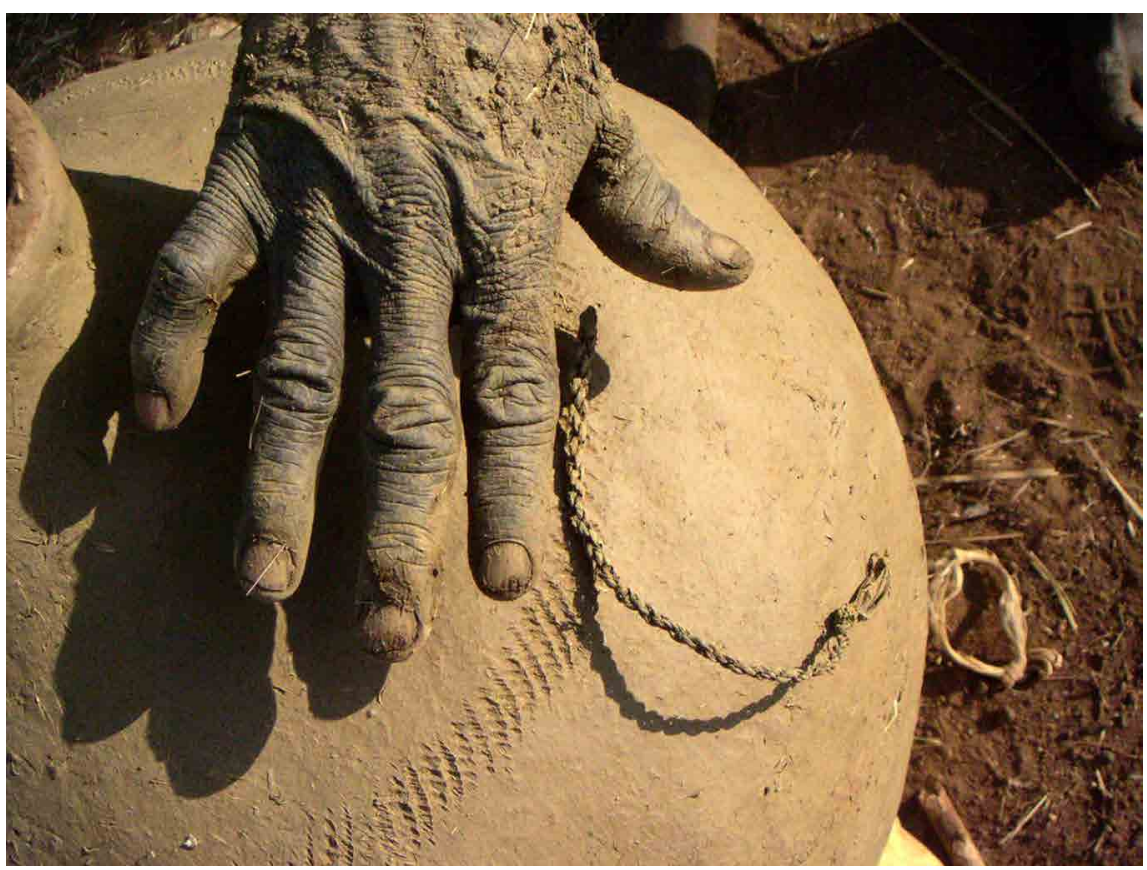

Figura 5. La textura de las cosas: una alfarera bertha muestra cómo aplica la impresión de cuerda sobre una cerámica para cerveza.

vos en mente). El plano del lugar utilizado por una comunidad nunamiut para descuartizar un reno transmite tanta información sobre la actividad diaria como un relato detallado de los aspectos simbólicos y sociales de la caza. Ya he mencionado que, durante las décadas de 1960 y 1970, se desarrollaron numerosos proyectos centrados en el análisis prolijo de asentamientos de comunidades no modernas (Watson 1979; Horne 1994), pero desafortunadamente esta tradición se interrumpió. La impresionante monografía de Gustavo Politis (2007) sobre los nukak es una excepción. Las fotografías y los planos incluidos en el libro son tan importantes en la narrativa como el propio texto (también Mans 2012). En un mundo representado así vemos gente, vemos su selva tropical, sus animales, sus casas, sus cerbatanas y sus hamacas. Sin embargo, como ya señalé mucho antes de que la etnoarqueología comenzara a dibujar y fotografiar cerámicas, dispersiones de artefactos y hornos, la antropología ya lo había estado haciendo durante décadas. En el caso de Etiopía, los trabajos de Eike Haberland (1963) y Straube (1963), entre otros, contienen abundante información visual y textual de casi todos los aspectos de la vida material.

En mi opinión, la relevancia de las texturas materiales es evidente. El significado no es suficiente para manifestar un mundo vivido
(Olsen 2003). Mi interés por las texturas surge simultáneamente de una fascinación por los primeros relatos etnográficos y una insatisfacción por las etnografías en las que difícilmente se puede obtener una impresión de cómo es la vida material de las personas, a no ser que indague en el ruido de fondo de las fotografías. Podríamos conocer casi todo sobre cosmología, percepciones de la enfermedad, espíritus, formas de violencia social, derechos sobre la propiedad de la tierra, ritos de paso e imaginación política. No es mi intención minimizar la enorme hazaña intelectual de la descripción densa etnográfica. Pero, al fin y al cabo, a menudo estas narraciones complejas y matizadas no trasmiten el sentido de la vida vivida. Son densas en significado, pero, para mí, esto no es suficientemente denso. Todavía tenemos que capturar la inmediatez de las cosas, el sonido rítmico de la piedra de moler y el tacto áspero de una cerámica usada (Fig. 5).

\section{Conclusión}

En este artículo he tratado de exponer en qué puede consistir un análisis arqueológico de las sociedades no modernas contemporáneas que ha dejado de ser etnoarqueológico: una arqueología del presente (González-Ruibal 
2006). Esta arqueología de las sociedades no modernas actuales encuentra su razón de ser en su materialidad, entendida en sentido lato: no solo lo que se conoce tradicionalmente como cultura material (o tecnología, en la tradición francesa), es decir, la cerámica, la metalurgia o las casas, si no toda la materialidad del mundo. Esto incluye tanto la tecnología como los paisajes, los cuerpos, las ruinas o el desecho. El estudio arqueológico de la materialidad del presente tiene que desarrollarse a dos niveles. Uno de los niveles podría denominarse profundo, ya que tiene que ver con la ontología y el inconsciente: es la forma en que lo ma- terial nos constituye como personas y como sociedad. El otro de los niveles, en cambio, nos devuelve a la superficie y se refiere a la experiencia cotidiana del mundo de la materia: la textura de las cosas. Al analizar estos dos niveles de la materialidad contemporánea seguimos, en cualquier caso, prestando un servicio analógico a la arqueología en general, pues nuestras investigaciones pueden utilizarse para alimentar la imaginación arqueológica (David y Kramer 2001) de la misma manera que lo vienen haciendo, desde hace décadas, no solo la etnoarqueología, sino también la antropología, la historia o la sociología.

\section{Bibliografía}

Alberti, B.; Marshall, Y. (2009): Animating Archaeology: Local Theories and Conceptually Open-Ended Methodologies. Cambridge Archaeological Journal, 19: 344-356.

Alberti, B.; Fowles, S.; Holbraad, M.; Marshall, Y.; Witmore, C. (2011): 'Worlds Otherwise': Archaeology, Anthropology, and Ontological Difference. Current Anthropology, 52 (6): 896-91.

Arnould, E.J.; Wallendorf, M. (1994): Market-oriented ethnography: interpretation building and marketing strategy formulation. Journal of Marketing Research, 31: 484-504.

Benjamin, W.; Scholem, G.; Adorno, T.W. (1994): The correspondence of Walter Benjamin, 1910-1940. University of Chicago Press, Chicago.

Binford, L.R. (1978): Nunamiut Archaeology. Academic Press, New York

Binford, L.R. (1991): When the going gets tough, the tough get going: Nunamiut local groups, camping patterns and economic organization. Ethnoarchaeological approaches to mobile campsites: huntergatherer and pastoralist case studies (C.S. Gamble, W.S. Boismier, eds.), International Monographs in Prehistory, Ann Arbor.

Boesch, E. E. (1991): Symbolic action theory and cultural psychology. Springer-Verlag, Berlin.

Bourdieu, P. (1977): Outline of a theory of practice. Cambridge University Press, Cambridge.

Bourdieu, P. (2001): La dominación masculina. Anagrama, Barcelona.

Braudel, F. (1966): El Mediterráneo y el mundo mediterráneo en la época de Felipe II. Fondo de Cultura Económica, México.

Castañeda, Q.E.; Matthews, C.N. (2008): Ethnographic Archaeologies: Reflections on Stakeholders and Archaeological Practice. AltaMira Press, Lanham, MD.

Connerton, P. (1989): How societies remember. Cambridge University Press, Cambridge.

Crossland, Z. (2009): Of clues and signs: the dead body and its evidential traces. American Anthropologist, 111(1): 69-80.

David, N.; Kramer, C. (2001): Ethnoarchaeology in action. Cambridge University Press, Cambridge.

Deetz, J. (1977): In small things forgotten. An archaeology of early American life. Anchor, New York.

Dobres, M.A. (2000): Technology and social agency: outlining a practice framework for archaeology. Blackwell, Oxford y Malden, MA.

Douny, L. (2007): The materiality of domestic waste. The recycled cosmology of the Dogon of Mali. Journal of Material Culture, 12(3): 309-331.

Edgeworth, M. (2006): The clearing: Heidegger and excavation. (Archaeolog.org). [URL: http://traumwerk. stanford.edu/archaeolog/2006/09/the_clearing_heidegger_and_exc.html.]

Evans-Pritchard, E. E. (1970): Nuer religion. Clarendon Press, Oxford.

Evans-Pritchard, E. E. (1992): Los Nuer. Anagrama, Barcelona.

Forbes, H. (2007): Meaning and identity in a Greek landscape. An archaeological ethnography. Cambridge University Press, New York.

Freud, S.; Phillips, A. (2006): The Penguin Freud Reader. Penguin, London.

Gallay, A. (2011): Pour une ethnoarchéologie théorique. Errance, Paris.

Geertz, C. (1973): The interpretation of cultures. Selected essays. Basic Books, New York.

Giansanti, G. (2004): Ultima Africa. White Star, Vercelli. 
Ginzburg, C. (1980): Morelli, Freud and Sherlock Holmes: clues and scientific method. History Workshop, 9: $5-36$.

Glassie, H. (1975): Folk housing in middle Virginia: a structural analysis of historical artifacts. University of Tennessee Press, Knoxville.

Glassie, H. (1999): Material culture. Indiana University Press, Bloomington.

Godelier, M. (2002): Surrogate for humans and for Gods. People and things. Social meditations in Oceania (M. Jeudy-Ballini, B. Juillerat, eds.), Carolina Academic Press, Durham.

González-Ruibal, A. (2006): Order in a disordered world. The Bertha house. Anthropos, 101(2): 379-402.

González-Ruibal, A. (2014): An archaeology of resistance. Time and materiality in an African borderland. Rowman \& Littlefield, Lanham, MD.

González-Ruibal, A.; Hernando, A.; Politis, G. (2011): Ontology of the self and material culture: arrow making among the Awá hunter-gatherers of the Brazilian Amazon forest. Journal of Anthropological Archaeology, 30 (1): 1-16.

Gosden, C. (1999): Archaeology and anthropology: a changing relationship. Routledge, London.

Griaule, M. (1938): Introduction méthodologique. Mission Dakar-Djibouti 1931-1933. Minotaure, 2: 7-11.

Grottanelli, V. (1940): Missione Etnografica nel Uo-llega Occidentale. Volume Primo. I Mao, Reale Accademia d'Italia. Centro Studi per l'Africa Orientale Italiana, Roma.

Haberland (1963): Galla Süd-Athiopiens. Kohlhammer, Stuttgart.

Hahn, H. P. (2003): Monographien zur materiellen kultur in Africa. Anthropos, 98: 19-29.

Hamilakis, Y. (2011): Archaeological ethnography: a multitemporal meeting ground for archaeology and anthropology. Annual Review of Anthropology, 40: 399-414.

Hamilakis, Y.; Anagnostopoulos, A. (2009): What is Archaeological Ethnography? Public Archaeology, 8 (2-3): 65-87.

Harrison, R. (2011): Surface assemblages. Towards an archaeology in and of the present. Archaeological Dialogues, 18(2): 141-161.

Hernando Gonzalo, A. (2012): La fantasía de la individualidad. Sobre la construcción sociohistórica del sujeto moderno. Katz Conocimiento.

Hodder, I. (1982): Symbols in action. Ethnoarchaeological studies of material culture. Cambridge University Press, Cambridge.

Hodder, I. (1986): Reading the past: current approaches to interpretation in archaeology. Cambridge University Press, Cambridge.

Hodder, I. (1987): Archaeology as long term history. Cambridge University Press, Cambridge.

Hodder, I. (1992): Theory and practice in archaeology. Routledge, London.

Hodder, I. (2012): Entangled: an archaeology of the relationships between humans and things. Wiley Blackwell, Oxford.

Hodder, I.; Cessford (2004): Daily practice and social memory in Çatal Höyuk. American Antiquity, 69 (1): $17-40$.

Horne, L. (1994): Village spaces. Settlement and society in Northeastern Iran. Smithsonian Institute Press, Washington D.C.

Hollander, J.A.; Einwohner, R.L. (2004): Conceptualizing resistance. Sociolocial Forum, 19 (4): 533-554.

Hurcombe, L. (2007): A sense of materials and sensory perceptions in concepts of materiality. World Archaeology, 39 (4): 532-545.

Ingold, T. (1990): Society, nature and the concept of technology. Archaeological Review from Cambridge, 9 (1): 5-17.

James, W. (1979): 'Kwanim Pa. The making of the Uduk people. Clarendon Press, Oxford.

James, W. (1988): The Listening Ebony. Moral Knowledge, Religion and Power among the Uduk of Sudan. Clarendon Press, Oxford.

Jedrej, C. (1995): Ingessana: The religious institutions of a people of the Sudan-Ethiopian borderland. Brill, Leiden.

Jones, A. (2007): Archaeology and memory. Cambridge University Press, Cambridge.

Knappett, C. (2002): Photographs, skeuomorphs and marionettes. Some thoughts on mind, agency and object. Journal of Material Culture 7(1): 97-117.

Knappett, C. (2012): Materiality. Archaeological Theory Today. $2^{\text {nd }}$ Edition (I. Hodder, ed.), Polity Press, Cambridge: 188-207.

Lane, P. J. (1994): The temporal structuring of settlement space among the Dogon of Mali: an ethnoarchaeological study. Architecture and order (M. Parker Pearson, C. Richards, eds.), Routledge, London: 196-216.

Lane, P. J. (1996): Rethinking ethnoarchaeology. Aspects of African Archaeology: papers from the $10^{\text {th }}$ Congress of the Pan African Association for Prehistory and Related studies (G. Pwiti, R. Soper, eds.), University of Zimbabwe Publications, Harare: 727-732. 
Lane, P.J. (2006): Present to past. Ethnoarchaeology. Handbook of Material Culture (C. Tilley, W. Keane, M. Küchler, M. Rowlands, P. Spyer, eds.), Sage, London: 402-424.

Latour, B. (1993): We have never been modern. Harvard University Press, Cambridge, MA.

Lemonnier, P. (1986): The study of material culture today: toward and anthropology of technical systems. Journal of Anthropological Archaeology, 5: 147-186.

Lemonnier, P. (1992): Elements for an anthropology of technology. Museum of Anthropology, University of Michigan, Ann Arbor.

Lemonnier, P. (2012): Mundane objects: Materiality and non-verbal communication. Left Coast Press, Walnut Creek, CA.

Leroi-Gourhan, A. (1965): Le geste et le parole. Vol. II. La memoire et les rhythmes. Albin Michel, Paris.

Le Roy Ladurie, E. (1975): Montaillou, village occitan, de 1294 à 1324. Gallimard, Paris.

Lucas, G. (2004): Modern disturbances: On the ambiguities of archaeology. Modernism/Modernity, 11(1): $109-120$.

Mans, J. (2012): Amotopoan trails. Recent archaeology of Trio movements. Sidestone Press, Leiden.

Meskell, L. (2005): Archaeological ethnography: conversations around Kruger National Park. Archaeologies, 1(1): $81-100$.

Miller, D. (1998): Material cultures: why some things matter. UCL Press, London.

Olivier, L. (2008): Le sombre abîme du temps. Mémoire et archéologie. Seuil, Paris.

Olsen, B. (2003): Material culture after text: re-membering things. Norwegian Archaeological Review, 36(2): 87-104.

Olsen, B. (2006): Scenes from a Troubled Engagement. Post-structuralism and Material Culture Studies. Handbook of Material Culture (C. Tilley, W. Keane, S. Kuechler, M. Rowlands and P. Spyer, eds.), Sage, London: 85-103.

Olsen, B. (2010): In defense of things. Archaeology and the ontology of objects. AltaMira Press, Lanham, MD.

Olsen, B.; M. Shanks, M.; Webmoor, T.; Witmore, C. (2012): Archaeology. The discipline of things. University of California Press, Berkeley.

Pauketat, T.R. (2001): Practice and history in archaeology. An emerging paradigm. Anthropological Theory, 1(1): 73-98.

Pearson, M.; Shanks, M. (2001): Theatre/archaeology. Routledge, London.

Pétréquin, P.; Pétréquin, A.M. (1999): La poterie en Nouvelle Guinée: savorfaire et transmission des téchniques. Journal de la Societé des Océanistes, 108: 71-101.

Pétréquin, P.; Pétréquin, A.M. (1993): Ecológie d'un outil. La hache de pierre en Irian Jaya (Indonésie). CNRS, Paris.

Politis, G. (2007): Nukak. Ethnoarchaeology of an Amazonian people. LeftCoast, Walnut Creek, CA.

Politis, G. (2015a): Ethnoarchaeology: Approaches to Fieldwork. Field Archaeology from Around the World. Ideas and approaches (M. Carver, B. Gaydarska, S. Montón-Subías, eds.), Springer: Nueva York: 83-88.

Politis, G. (2015b): Reflections on Contemporary Ethnoarchaeology. Pyrenae, 46(1): 41-83.

Raab, L.M.; Goodyear, A.C. (1984): Middle-range theory in archaeology: a critical review of origins and applications. American Antiquity, 62 (2): 255-268.

Rosaldo, R. (1986): From the door of his tent: the fieldworker and the inquisitor. Writing culture: the poetics and politics of ethnography (J. Clifford, G. Marcus, eds.), University of California Press, Berkeley.

Roux, V. (2007): Ethnoarchaeology: a non-historical science of reference necessary for interpreting the past. Journal of Archaeological Method and Theory, 14 (2): 153-178.

Saunders, N.J. (2003): Trench-art: materialities and memories of war. Berg, Oxford.

Schiffer, M. B. (1972): Archaeological context and systemic context. American Antiquity, 37 (2): 156-165.

Schiffer, M. (1991): The portable radio in American life. University of Arizona Press, Tucson.

Schmidt, P.R. (2010): The play of tropes. Ethnoarchaeology as metonymy. Ethnoarchaeology, 2 (2): 131152.

Schwartz, B. (1997): Culture and power. The sociology of Pierre Bourdieu. University of Chicago Press, Chicago.

Silliman, S. (2001): Agency, practical politics and the archaeology of culture contact. Journal of Social Archaeology, 1 (2): 190-209.

Sinclair, A. (2000): This is an article about archaeology as writing. Interpretative archaeology. A reader (J. Thomas, ed.), Leicester University Press, Leicester: 474-488.

Storr, M. (2003): Latex and lingerie: shopping for pleasure at Ann Summers parties. Berg, Oxford.

Straube, H. (1963): Westkuschitische volker siid-Athiopiens. Kohlhammer, Stuttgart.

Taussig, M. (2004): My cocaine museum. Chicago University Press, Chicago.

Theis, J. (1995): Nach der razzia. Ethnographie und Geschichte der Koma. Trickster, Münster. 
Tilley, C. (1996): An ethnography of the Neolithic: early prehistoric societies in southern Scandinavia. Cambridge University Press, Cambridge.

Tilley, C. (2006): Objectification. Handbook of Material Culture (C. Tilley, W. Keane, M. Küchler, M. Rowlands, P. Spyer, eds.), Sage, London: 60-73.

Verhoeven, M. (1999): An archaeological ethnography of a Neolithic community: space, place and social relations in the burnt village at Tell Sabi Abyad, Syria. Netherlands Instituut voor het Nabije Oosten, Leiden.

Watson, P. J. (1979): Archaeological ethnography in western Iran. Viking Fund publications in Anthropology, 57. Tucson, Arizona.

Witmore, C. (2006): Vision, media, noise and the percolation of time. Symmetrical approaches to the mediation of the material world. Journal of Material Culture, 11(3): 267-292.

Witmore, C. (2009): Prolegomena to open pasts: on archaeological memory practices. Archaeologies, 5 (3): 511-545.

Witmore, C.; Webmoor, T. (2008): Things are us! A commentary on human/things relations under the banner of a "social" archaeology. Norwegian Archaeological Review, 41 (1): 53-70.

Wylie, A. (1985): The reaction against analogy. Advances in Archaeological Method and Theory, 8: 63-111. 